\title{
Design and Analysis of Lightweight Automotive Component for Turbocharger Units
}

\author{
Mehmet Cagri Tuzemen ${ }^{1, *}$, Mehmet Agaoglu ${ }^{2}$, Mehmet Karakaya $^{2}$, Elmas Salamei ${ }^{1}$,Gokhan Kucukturk ${ }^{1}$ \\ ${ }^{1}$ Mechanical Engineering Department, Gazi University, Turkey \\ ${ }^{2}$ Ozler Plastik PLC, Turkey
}

Copyright $(\subset 2015$ by authors, all rights reserved. Authors agree that this article remains permanently open access under the terms of the Creative Commons Attribution License 4.0 International License

\begin{abstract}
Nowadays global warming in parallel with air pollution is a significant problem. One of the major causes is the conventional fuel-powered automobile. This study focuses on reducing global warming caused by automobiles. This paper presents the results of redesign and analysis of piping component of a turbocharger unit from a new material in order to reduce the weight and unify the component from only one material. The existing component is composed of three different parts and materials. With the new design, in addition to the lightweight property, the component is designed in such a way that two separate parts of existing design are unified in a single part which simplifies the assembly of the component to the turbocharger unit. The design starts with choosing the convenient material to satisfy the necessary service conditions such as high temperature and pressure. Two different materials are considered for the analyses which are aluminium alloy and PA66+PA6-HI glass fiber reinforced plastic matrix composite material. Firstly, finite element analyses were performed by using a commercial software. The results of the finite element analyses showed that both materials showed resistance to tensile load of $4000 \mathrm{~N}$ and pressure of $0.4 \mathrm{MPa}$ at $22^{\circ} \mathrm{C}$. However, if two separate parts were unified with a single part made of aluminium alloy, this component would fail under pressure of $0.4 \mathrm{MPa}$ at $150^{\circ} \mathrm{C}$ and $210^{\circ} \mathrm{C}$, while the component made of PA66+PA6-HI glass fiber reinforced plastic matrix composite material resisted the pressure at higher temperatures. Tensile tests under $4000 \mathrm{~N}$ and pressure tests under $0.4 \mathrm{MPa}$ at temperatures of $22^{\circ} \mathrm{C}, 150^{\circ} \mathrm{C}$ and $210^{\circ} \mathrm{C}$ were carried out on the component produced by PA66+PA6-HI glass fiber reinforced plastic matrix composite material. The same results were observed with those obtained by the finite element analyses. The design with the composite material satisfies both the mechanical and lightweight considerations.
\end{abstract}

Keywords Finite Element Analysis, Lightweight Design, Material Substitution

\section{Introduction}

Automobiles have become an indispensable part of life with rapidly increasing numbers especially in the developing countries. However, there are certain negative aspects of the increasing numbers of automobiles among which the pollution is regarded as the most critical one. There are various research studies to reduce the pollutions and one of them is using lighter parts that will perform the same function instead of using conventional materials. It is well known that both the fuel consumption and the $\mathrm{CO}_{2}$ emission are decreased by reducing the weight of cars. Along with rapidly increasing number of cars and fuel consumptions in the recent years, there has been social pressure on the automobile industry to design and manufacture new cars which will produce less pollution for the environment [1]. Since average fuel consumption is directly proportional to the weight of the vehicle, increased weight means that it will consume more fuel and therefore it is less ecological [2]. To decrease fuel consumption and emissions, lighter materials are selected instead of using traditional and conventional materials such as iron and steel [3]. It is reported that 56.69 $\mathrm{kg}$ decrease in the weight results in driving of $0.09-0.21 \mathrm{~km}$ more with the same amount of fuel [4]. Generally, there are two approaches to decrease the weight of an existing vehicle: (i) making structural improvement and (ii) replacement of materials/using new materials. Previous works reveal that the weight of a vehicle could be reduced $7 \%$ with some structural optimizations [5]. The characteristics of the product and production costs are some of the properties in the material selection for the new design or re-design of a vehicle component [6].

In this study, redesign and analysis of piping component of a turbocharger unit from a new material is considered in order to reduce the weight and to unify the component from only one material. Finite element analyses were performed and prototype was produced and tested. The results are introduced in this paper. 


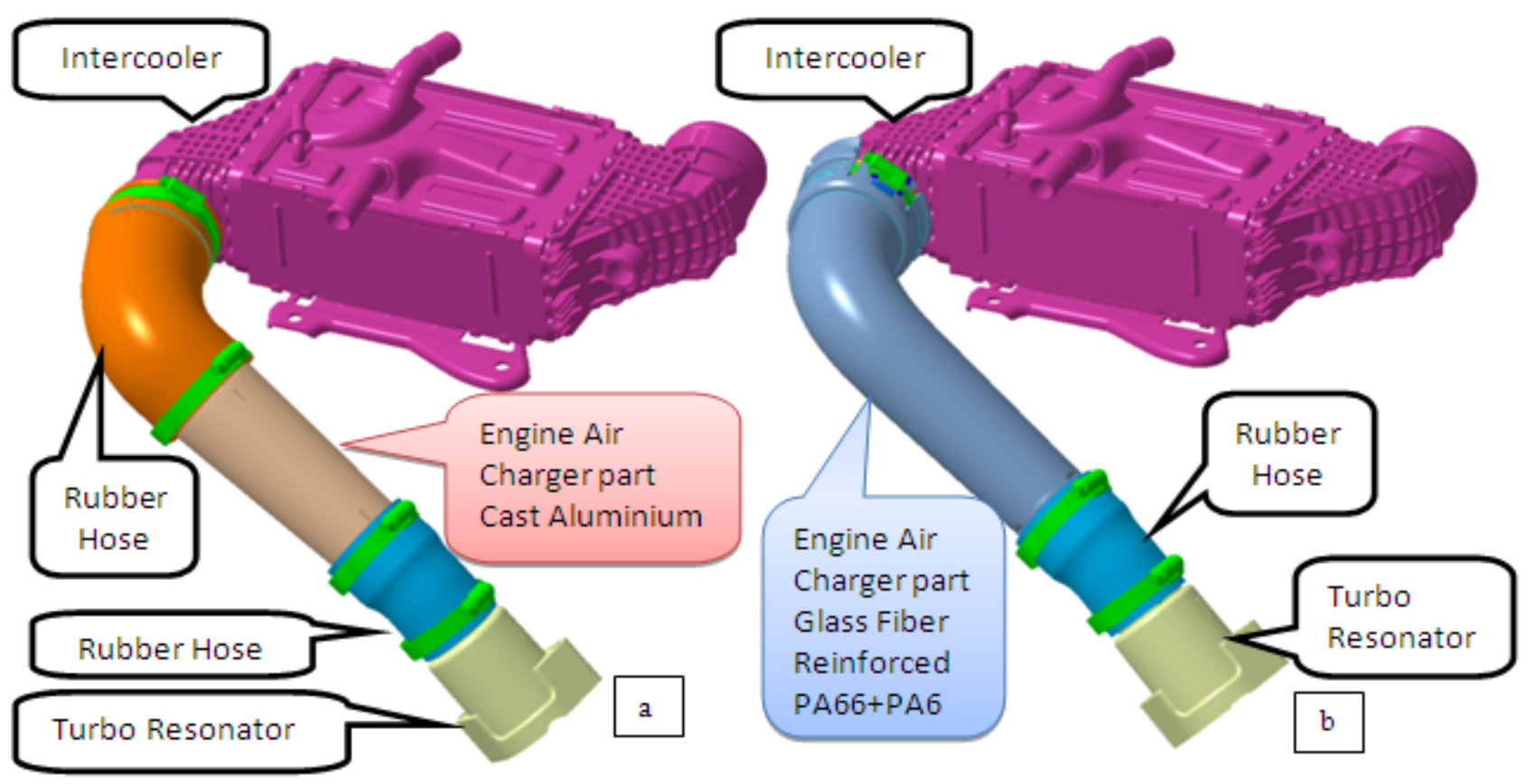

Figure 1. (a) Previous design (b) current design

\section{Design Phase}

The components of a piping system in the existing design are shown in Figure 1 (a). It contains a rubber hose, cast aluminum pipe, another rubber hose and turbo resonator. The turbo resonator is then connected to the turbocharger unit. Two rubber hoses in the existing design give flexibility to the piping system which is used to assemble the piping units to intercooler on one side and turbocharger on the other side easily. Two main disadvantages arise in the existing design: the part weight and the number of different parts. Therefore, a new design is performed in this study which is shown in Figure 1 (b) schematically. The new design unifies the first rubber hose (connected to the intercooler) and cast aluminium parts into one part with a new material. The new material is selected to be PA66+PA6-HI glass fiber reinforced plastic matrix composite material which has good mechanical and thermal resistance and low density. The new design should be lighter than the previous design. First, certain changes are done in the design by taking the position of the part and geometric limitations into consideration. The part to be redesigned will be connected with intercooler and rubber hose from its ends. Since pressurized air will be passing through the redesigned part, such connections should exhibit leak proof characteristics under high pressure.

For this purpose, as shown in Figure 1, the redesigned part at the position of being connected to intercooler and rubber hose has rings oriented to inner side found inside and clamps are used outside. The material of ring used in the section of intercooler is rubber, the ring at rubber hose and materials of clamps at both sides are selected to be metal. As a result of design improvements, the parts and the method of making connections were given their final form. Figure 1 shows the previous and current design of the piping system.

\section{Finite Element Analysis}

Force Analysis. Pressurized air passing through inside of the redesigned part will create tensions on it. The desired mechanical characteristic for this part is its durability under especially a load of $4000 \mathrm{~N}$ and it should not be damaged. Also, the connections from both ends should be safe enough. Once the mechanical limitations have been determined, finite element analyses are performed by using one of the commercial softwares to check the safety factor. In the finite element analyses, 507873 nodes and 328338 elements are formed. Material of the redesigned part to be analyzed is first considered to be several aluminium alloys. They are selected to be Al 3003, Al 6061-T6 and Al 7075-T6. For the redesigned part having a thickness of $3 \mathrm{~mm}$, the required support and loading conditions are formed as shown in Figure 2. Part marked $\mathrm{A}$ is intercooler (connecting side) and it is fixed at the bottom surface of the model whereas from the surface marked B force is applied to the redesigned part.

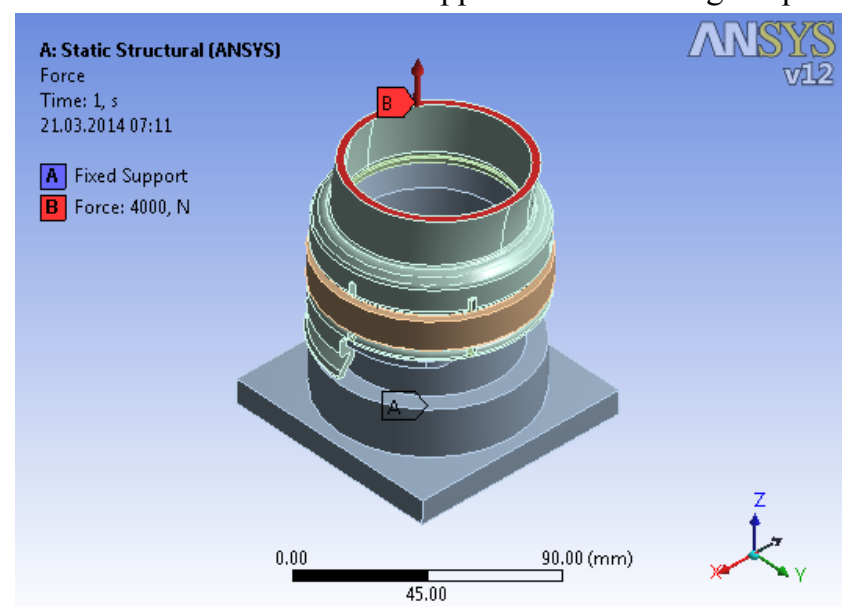

Figure 2. Fixed supported and force applied surfaces 
Table 1. Force analyses results for aluminium alloys

\begin{tabular}{|c|c|c|c|c|c|}
\hline & Force [N] & Deformation [mm] & Strain [mm/mm] & Stress [MPa] & Safety Factor \\
\hline \multirow{4}{*}{ AL 7075-T6 } & 2000 & 0.007953 & 0.000251 & 17.865 & 28.268 \\
\cline { 2 - 6 } & 4000 & 0.015906 & 0.000503 & 35.730 & 14.134 \\
\cline { 2 - 6 } & 6000 & 0.023859 & 0.000754 & 53.595 & 9.422 \\
\hline \multirow{5}{*}{ AL 6061-T6 } & 8000 & 0.031812 & 0.001006 & 71.460 & 7.066 \\
\cline { 2 - 7 } & 2000 & 0.008164 & 0.000258 & 17.862 & 15.452 \\
\cline { 2 - 6 } & 4000 & 0.016329 & 0.000517 & 35.724 & 7.726 \\
\hline \multirow{4}{*}{ AL 3003 } & 6000 & 0.024493 & 0.000776 & 53.585 & 5.150 \\
\cline { 2 - 6 } & 8000 & 0.032657 & 0.001035 & 71.447 & 3.863 \\
\cline { 2 - 6 } & 2000 & 0.008057 & 0.000255 & 17.863 & 6.997 \\
\cline { 2 - 6 } & 4000 & 0.016144 & 0.000510 & 35.727 & 3.498 \\
\hline
\end{tabular}

Table 2. Certain mechanical properties of the used materials

\begin{tabular}{|c|c|c|c|c|}
\hline & Al 3003 & Al 6061-T6 & Al 7075-T6 & PA66+PA6-HI \\
\hline Tensile Yield Strength [MPa] & 125 & 276 & 505 & 55 \\
\hline Tensile Ultimate Strength [MPa] & 130 & 310 & 572 & 70 \\
\hline Modulus of Elasticity [GPa] & 70 & 69 & 71 & 2.7 \\
\hline $\begin{array}{c}\text { Coefficient of Thermal Expansion } \\
10^{-6}\left[{ }^{\circ} \mathrm{C}^{-1}\right]\end{array}$ & 23.2 & 23.6 & 23.4 & 30 \\
\hline Density $\left[\mathrm{g} / \mathrm{cm}^{3}\right]$ & 2.73 & 2.70 & 2.80 & 1.24 \\
\hline
\end{tabular}

Table 3. Force analyses results for PA66+PA6-HI

\begin{tabular}{|c|c|c|c|c|c|}
\hline & Force [N] & Deformation $[\mathrm{mm}]$ & Strain $[\mathrm{mm} / \mathrm{mm}]$ & Stress [MPa] & Safety Factor \\
\hline \multirow{4}{*}{ PA66+PA6-HI } & 2000 & 0.177310 & 0.006331 & 19.241 & 3.122 \\
\cline { 2 - 6 } & 4000 & 0.354620 & 0.012662 & 38.482 & 1.561 \\
\cline { 2 - 6 } & 6000 & 0.531930 & 0.018993 & 57.724 & 1.041 \\
\cline { 2 - 6 } & 8000 & 0.709240 & 0.025324 & 76.965 & 0.781 \\
\hline
\end{tabular}

For the three different aluminium alloys, tensile force analyses were performed for 4 different forces which were $2000 \mathrm{~N}, 4000 \mathrm{~N}, 6000 \mathrm{~N}$ and $8000 \mathrm{~N}$ respectively. The three materials were found to be durable under the desired value of $4000 \mathrm{~N}$ tensile force. Table 1 shows the results of force analysis. In order to reduce the weight of the new design, a different material was also considered and subjected to force analysis as well. For this purpose, PA66+PA6-HI glass fiber reinforced plastic matrix composite material having less density as compared to aluminium alloy was selected. Some of the mechanical characteristics of aluminium alloys and the PA66+PA6-HI material are shown in Table 2 [7]. The same finite element analysis performed for aluminium alloys was carried out for the new material under the forces of $2000 \mathrm{~N}$, $4000 \mathrm{~N}, 6000 \mathrm{~N}$ and $8000 \mathrm{~N}$. Among the applied forces, it was observed that the new material satisfied the required safety factor for the $4000 \mathrm{~N}$ applied force value. The results of analyses are shown in Table 3.

Pressure Analysis. The redesigned part which is subjected to force analysis will be subjected to hot air exiting from the engine of the vehicle at the same time. The desired mechanical characteristic is required to be durable under a pressure of $0.4 \mathrm{MPa}$ at temperature of $210^{\circ} \mathrm{C}$. For the pressure analysis, only the redesigned part was prepared as shell and transferred to the finite element software. Similar to the force analysis, the static structural module of the software was selected. For this particular analysis, rather than using default mesh size, smaller mesh size which was selected to be $1 \mathrm{~mm}$ was used. Thus by increasing the number of nodes and elements, more precise results were obtained to reflect the real operating condition. After formation of the meshes, 74370 nodes and 74293 elements were formed on the finite element model. The analyses were first performed for aluminium materials of $\mathrm{Al}$ 3003, Al 6061-T6 and Al 7075-T6.

As it can be seen in Figure 3, the model was fixed at both ends where the clamps are located. The internal pressure was set to $0.4 \mathrm{MPa}$ and first analysis was performed at the 
temperature of $22^{\circ} \mathrm{C}$. At this temperature, no damage was observed on the models. Next analyses were performed at temperatures of $150^{\circ} \mathrm{C}$ and $210^{\circ} \mathrm{C}$ respectively. All of the three materials were subjected to damage under these temperatures. To prevent formation of damage, the thickness of the material was increased to $4 \mathrm{~mm}$ and analyses were repeated under the pressure of $0.4 \mathrm{MPa}$ again. However, the aluminium alloy parts could not keep their durability at this pressure, that is, under the temperatures of $150^{\circ} \mathrm{C}$ and $210^{\circ} \mathrm{C}$. It was observed that the maximum stress occurs around point A (See Figure 8) which is the connection point to the intercooler. It should be noted that the connection point to the intercooler is made with rubber hose in the existing design. Also, the average diameter of the rubber hose is higher than that of the aluminium pipe. As an alternative to the existing design, the rubber hose part is unified with the aluminium pipe with the same material. The finite element analyses revealed that a unified redesign with aluminium may not satisfy the required safety factor. At this point, successful results might be obtained by increasing the thickness of material at higher levels, or by decreasing the diameter of the pipe on the intercooler connecting point (point A). However, even a move from $2 \mathrm{~mm}$ thickness to 4 $\mathrm{mm}$ resulted in $100 \%$ increase in part weight. On the other hand, the main objective is to have a durable part as well as having a light weight component. Results of analysis for aluminium alloys are shown in Table 4.

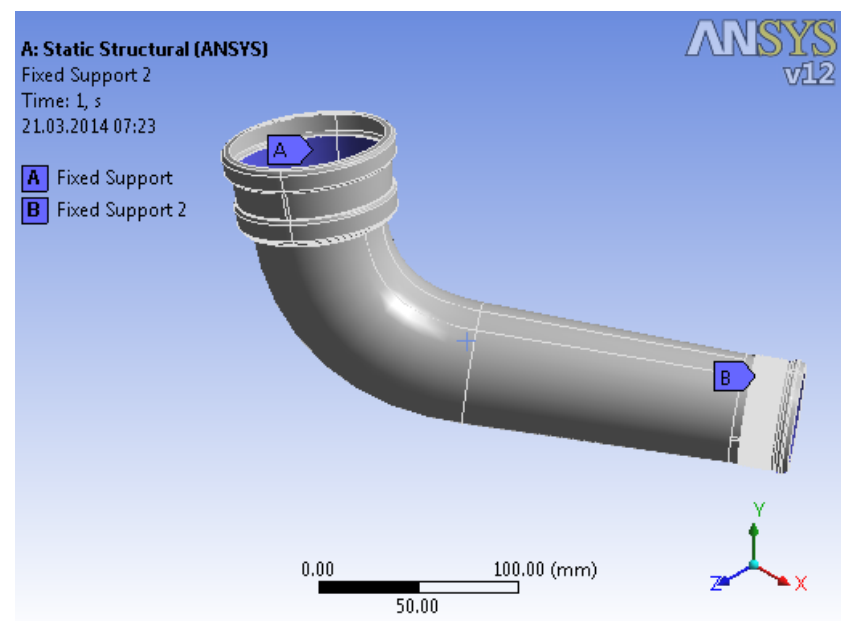

Figure 3. Fixed supported surfaces

Table 4. Pressure analysis results of aluminium alloys

\begin{tabular}{|c|c|c|c|c|c|c|}
\hline & $\begin{array}{c}\text { Thickness } \\
\text { [mm] }\end{array}$ & Temperature $\left[{ }^{\circ} \mathrm{C}\right]$ & Deformation [mm] & $\begin{array}{c}\text { Strain } \\
{[\mathrm{mm} / \mathbf{m m}]}\end{array}$ & Stress [MPa] & Safety Factor \\
\hline \multirow{6}{*}{ AL 7075-T6 } & \multirow{3}{*}{3} & 22 & 0.006939 & 0.000181 & 12.897 & 44.905 \\
\hline & & 150 & 0.691160 & 0.001111 & 738.700 & 0.784 \\
\hline & & 210 & 1.012300 & 0.001632 & 1052.600 & 0.549 \\
\hline & \multirow{3}{*}{4} & 22 & 0.004418 & 0.000115 & 8.173 & 72.035 \\
\hline & & 150 & 0.620420 & 0.001076 & 715.610 & 0.822 \\
\hline & & 210 & 0.909600 & 0.001580 & 1019.200 & 0.577 \\
\hline \multirow{6}{*}{ AL 6061-T6 } & \multirow{3}{*}{3} & 22 & 0.007140 & 0.000186 & 12.897 & 24.552 \\
\hline & & 150 & 0.697360 & 0.011208 & 707.970 & 0.447 \\
\hline & & 210 & 1.021300 & 0.016465 & 998.430 & 0.316 \\
\hline & \multirow{3}{*}{4} & 22 & 0.004546 & 0.000118 & 8.173 & 39.359 \\
\hline & & 150 & 0.625890 & 0.001085 & 685.900 & 0.469 \\
\hline & & 210 & 0.917590 & 0.015944 & 966.800 & 0.332 \\
\hline \multirow{6}{*}{ AL 3003} & \multirow{3}{*}{3} & 22 & 0.007038 & 0.000184 & 12.897 & 9.247 \\
\hline & & 150 & 0.685560 & 0.001101 & 706.060 & 0.203 \\
\hline & & 210 & 1.004000 & 0.001618 & 995.740 & 0.143 \\
\hline & \multirow{3}{*}{4} & 22 & 0.004481 & 0.000116 & 8.173 & 17.832 \\
\hline & & 150 & 0.615290 & 0.001067 & 684.050 & 0.213 \\
\hline & & 210 & 0.902040 & 0.015673 & 964.190 & 0.151 \\
\hline
\end{tabular}

Table 5. Pressure analysis results of PA66+PA6-HI

\begin{tabular}{|c|c|c|c|c|c|c|}
\hline & Thickness [mm] & Temperature $\left[{ }^{\circ} \mathrm{C}\right]$ & Deformation $[\mathrm{mm}]$ & Strain $[\mathrm{mm} / \mathrm{mm}]$ & Stress $[\mathrm{MPa}]$ & Safety Factor \\
\hline \multirow{4}{*}{3} & 22 & 0.163320 & 0.004587 & 12.764 & 4.082 \\
\cline { 3 - 8 } & \multirow{3}{*}{ PA66+PA6-HI } & 150 & 1.211500 & 0.018379 & 21.135 & 2.540 \\
\cline { 3 - 8 } & & 210 & 1.777000 & 0.026918 & 21.176 & 2.536 \\
\cline { 3 - 8 } & \multirow{3}{*}{4} & 22 & 0.103550 & 0.002905 & 8.083 & 6.497 \\
\cline { 2 - 8 } & & 150 & 1.019800 & 0.014131 & 16.250 & 3.495 \\
\cline { 2 - 8 } & & 210 & 1.496300 & 0.020752 & 16.325 & 3.487 \\
\hline
\end{tabular}




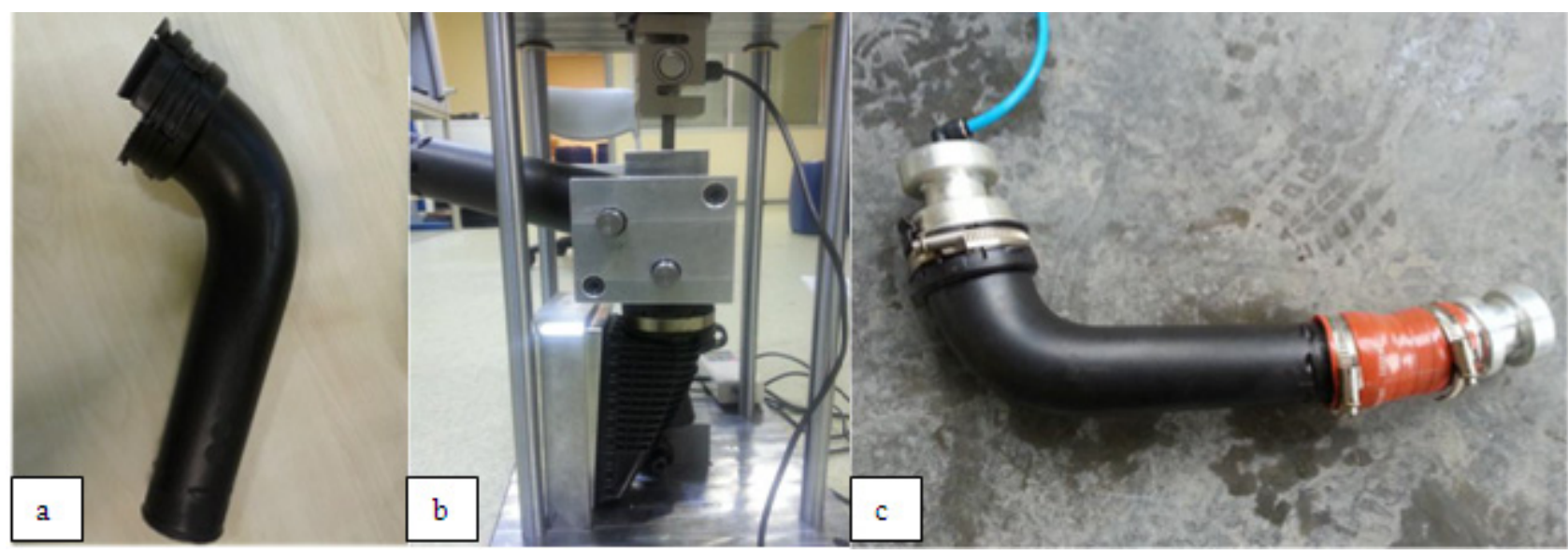

Figure 4. (a) Test specimen, (b) tensile testing apparatus, (c) pressure testing apparatus

In order to meet the main objective of the redesign, instead of aluminium alloys, the PA66+PA6-HI material (which passed the force analysis already) was used in the unified model. The redesign was first made with $4 \mathrm{~mm}$ material thickness and subjected to analysis. Under pressure of 0.4 $\mathrm{MPa}$ and air temperature of $22^{\circ} \mathrm{C}, 150^{\circ} \mathrm{C}$ and $210^{\circ} \mathrm{C}$ respectively, analyses were carried out and no damage was observed in these finite element analyses. Then, the material thickness of $4 \mathrm{~mm}$ is reduced to $3 \mathrm{~mm}$ and the new design was subjected to pressure analysis. It was observed that the new thickness was enough to satisfy the safety factor. Results of these analyses are shown in Table 5.

\section{Experimental Procedure}

According to the data generated from finite element software, the redesigned part was produced from the material PA66+PA6-HI, having material thickness of $3 \mathrm{~mm}$. The new part was produced by using blow molding method which is more cost effective production approach than the similar counterparts. The prototype was than subjected to some tests which were previously determined in test orders. In the test performed in laboratory settings, the narrow edge of the product was closed with the fixture contained in the tensile apparatus at the other edge part by using the original counterpart. At an environmental temperature of $22^{\circ} \mathrm{C}$, force was linearly increased until $4000 \mathrm{~N}$ was reached. No damaged was observed. The applied force was further increased and at $4572 \mathrm{~N}$ it was observed that there was breaking apart in the product. Since the desired maximum force value was attained, the test was completed successfully.

As the next step for pressure testing at outside environment, both edges of the part were fixed with aluminium apparatuses and clamps in such a way that it could not take air in and assembled. The part was kept at $150^{\circ} \mathrm{C}$ temperature for 1000 hours and air pressure was applied. At the working pressure of the product (which is 0.4 MPa) no deformation, separation, leaking at the sample or in the assembled region was observed. Therefore the test was completed successfully.

\section{Results and Discussion}

The aim of this study is to redesign an existing piping system in a turbocharger unit such that the desired mechanical characteristics are satisfied, the part is unified, lightweight and is easy to be manufactured. The finite element analyses revealed that unification of the parts with aluminium in the new design (without changing geometry) may not be sufficient especially with respect to high temperature. To satisfy the required safety factor, the thickness of the material (aluminium) could be further increased but this would increase the weight of the unified design. For this reason, the material was changed and PA66+PA6-HI glass fiber reinforced plastic matrix composite material was used in the new design. The finite elements analyses performed for the new material showed acceptable results especially at high temperatures under which aluminium alloys were not durable. The reason why the aluminium alloys are not durable especially under such temperatures may be the thermal stress which is given in the following formula:

$$
\sigma=\mathrm{E} \alpha \Delta \mathrm{T}
$$

The thermal stress $(\sigma)$ linearly depends on elastic modulus (E), coefficient of thermal expansion $(\alpha)$ and temperature change $(\Delta \mathrm{T})$. It can be seen from Table 2 that the most important element of these three variables is the elasticity modulus. Temperature changes are the same for all materials. Since the thermal expansion coefficients of the materials are close to each other, they do not create big differences on the thermal stresses. On the other hand, elasticity modules of the materials (aluminium alloys and the PA66+PA6-HI), which create big differences on the thermal stresses at high temperatures, are different. Although aluminium alloys have high yield strengths compared to the PA66+PA6-HI, they were damaged at high temperatures due to their higher thermal stresses.

In terms of production methods, the production of the unified part with PA66+PA6-HI material could be easier as 
compared to that of the same part made of an aluminium alloy. It should be noted that the part with PA66+PA6-HI material could be produced by using blow molding method which is a cost effective production methodology. In addition to its cost effective production method, the redesigned part with PA66+PA6-HI material will be flexible enough to be assembled to the solid intercooler side as the mouth of the pipe can easily be shaped and fixed by using clamps which is not possible for the aluminium alloy material case.

Figures 6 (a), (b), (c) and (d) show the von-Mises stress distributions under $4000 \mathrm{~N}$ force for the materials of $\mathrm{Al} 3003$, Al 6061-T6, Al 7075-T6 and PA66+PA6-HI materials respectively. It can be seen from the figures that for all materials the maximum stresses are between $35 \mathrm{MPa}$ to 38 $\mathrm{MPa}$ and very close to each other.

Although the stresses for different materials are close to each other, it can be seen from Figure 5 that the safety factor of aluminium alloys having higher yield strength is higher than that of PA66+PA6-HI material.

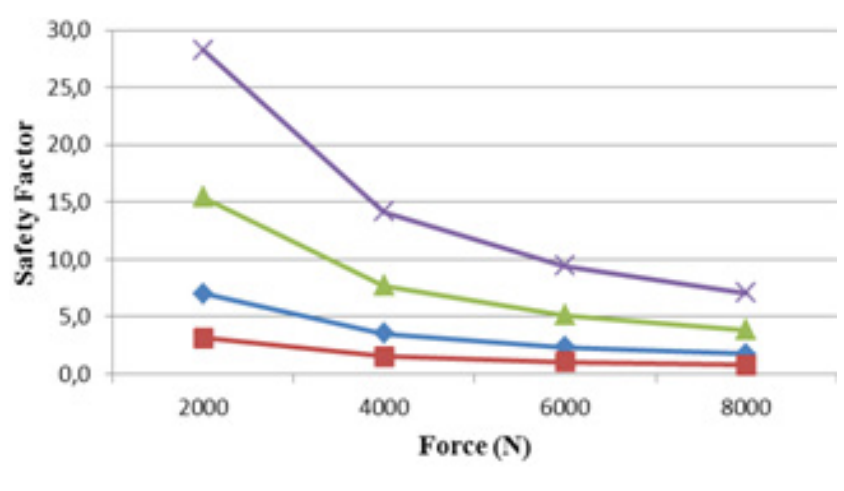

—Al $3003 \longrightarrow$ Al 6061-T6 $\longrightarrow$ Al 7075-T6 -PA66+PA6-HI

Figure 5. Effect of force on safety factor

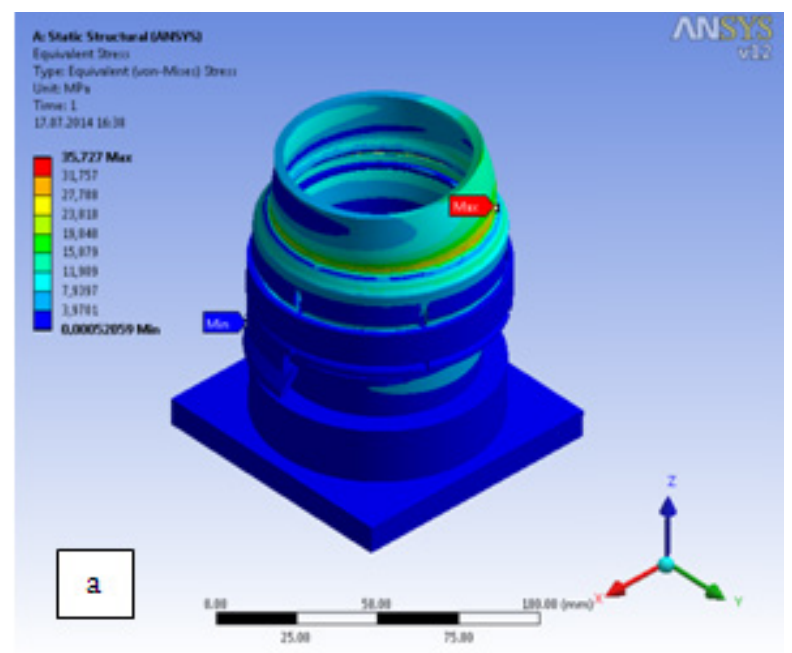

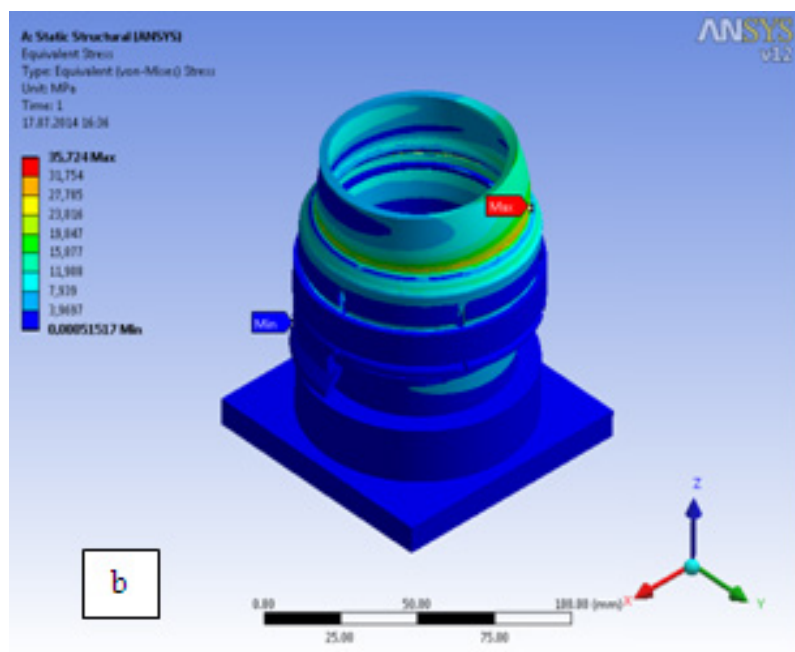
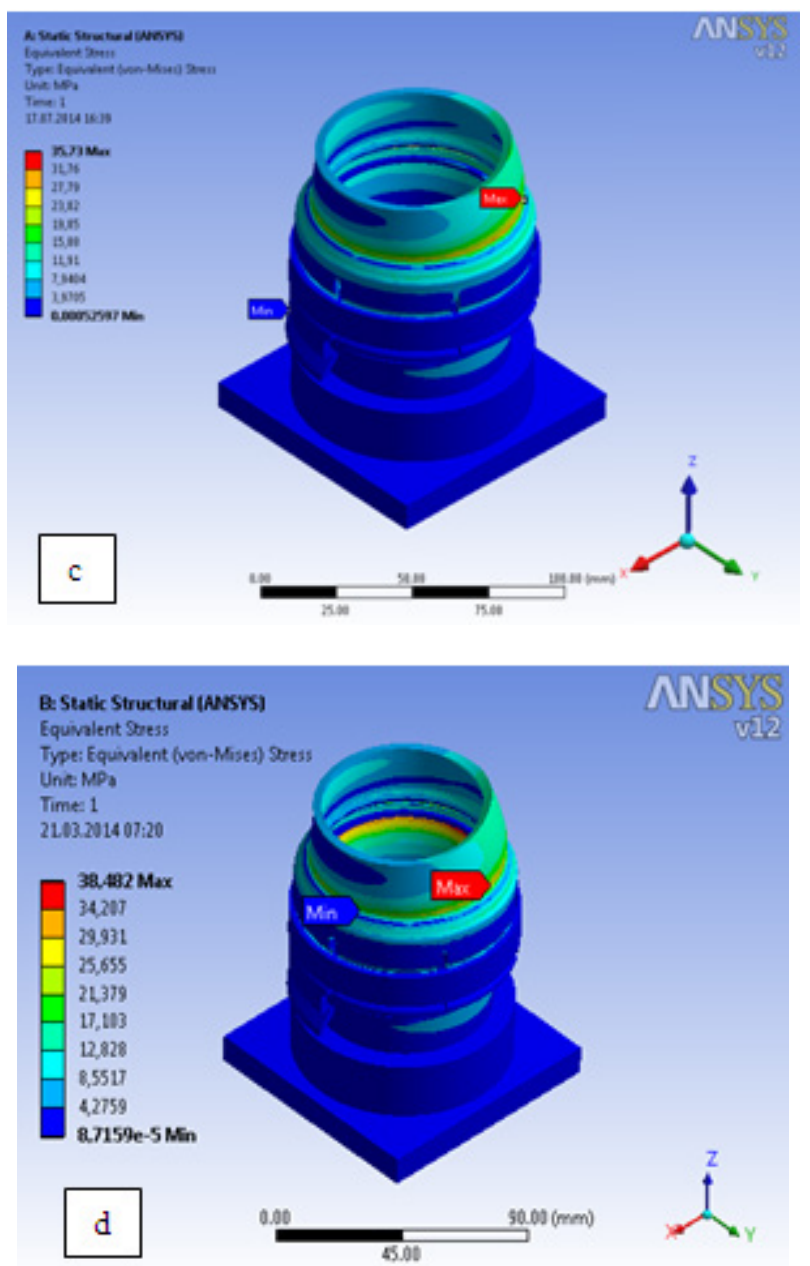

Figure 6. Tensile test results of (a) $\mathrm{Al}$ 3003, (b) Al 6061-T6, (c) Al 7075-T6, (d) PA66+PA6-HI 


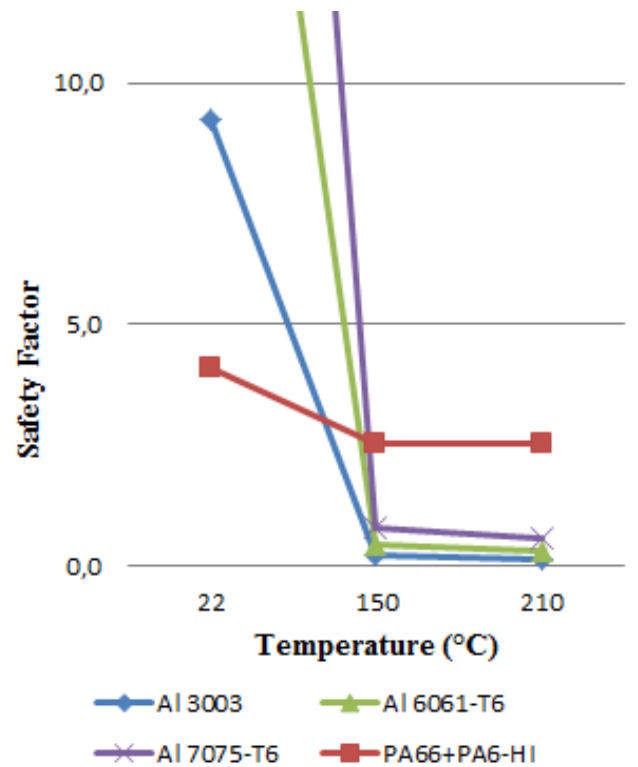

Figure 7. Effect of temperature on safety factor
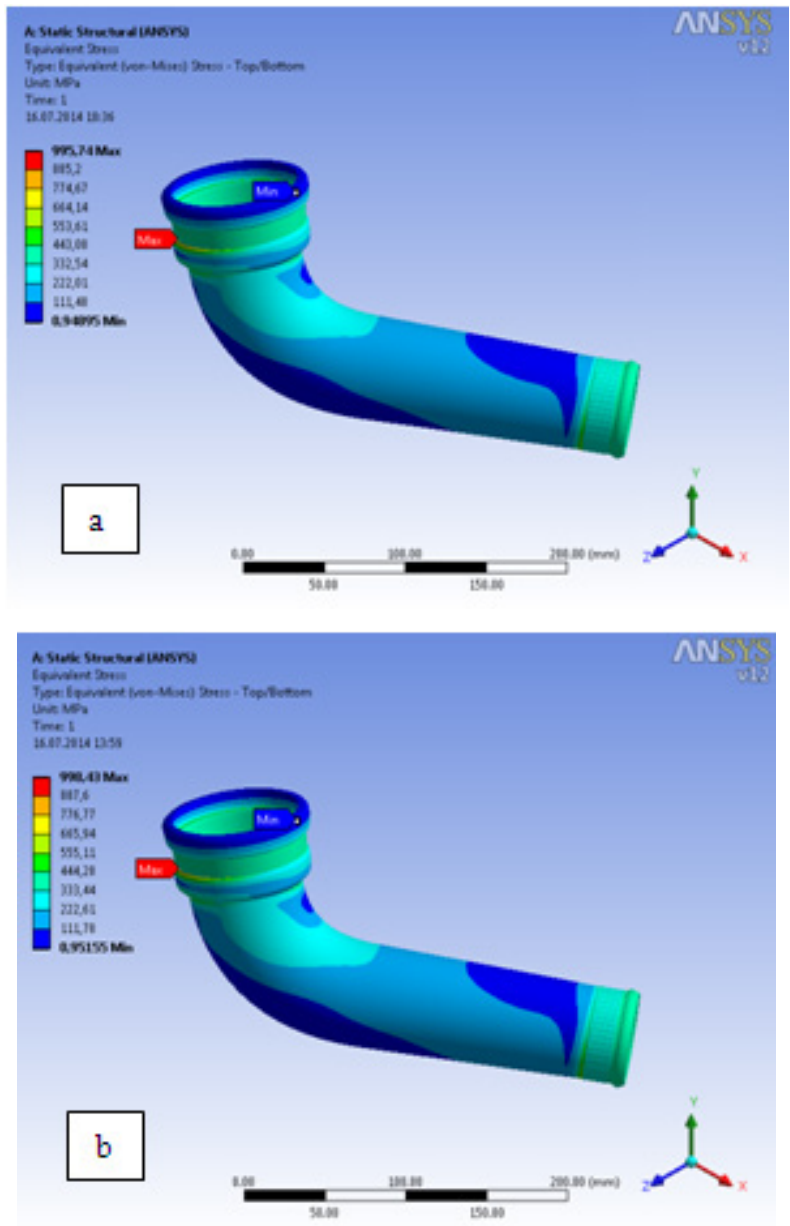
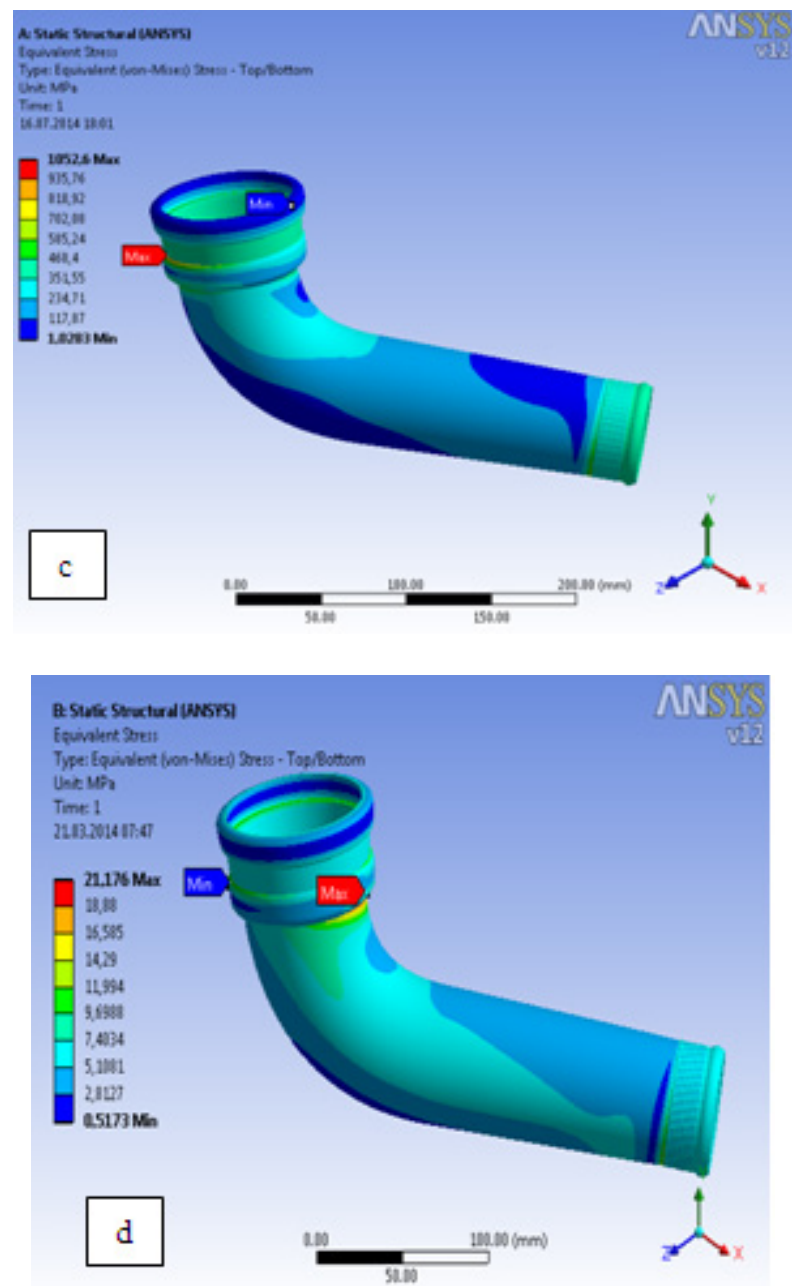

Figure 8. Pressure test results of (a) Al 3003, (b) Al 6061-T6, (c) Al 7075-T6, (d) PA66+PA6-HI at $210^{\circ} \mathrm{C}$

Figures 8 (a), (b), (c) and (d), show the von-Mises stress distribution under $0.4 \mathrm{MPa}$ pressure at $210^{\circ} \mathrm{C}$ by using the $\mathrm{Al}$ 3003, Al 6061-T6 Al 7075-T6 and PA66+PA6-HI materials respectively. At this temperature, stress distribution of aluminium alloys appeared to be very close to each other but the stress of the model made by using the PA66+PA6-HI material was rather low. As a result of such analysis done by using a material thickness of $3 \mathrm{~mm}$, it was observed that the aluminium alloys could not resist to a pressure value of 0.4 $\mathrm{MPa}$ at high temperatures. Figure 7 illustrates the effect of elasticity module at high temperatures on the stress distribution. As depicted in Figure 7, the safety factor of aluminium alloys rapidly decreased to below one at high temperatures. 


\section{Conclusions}

- Along with superior properties of PA66+PA6-HI material at high temperatures, one of its most important characteristics is its low density. The weights of models designed in computer with a material thickness of $3 \mathrm{~mm}$ by using $\mathrm{Al} \mathrm{3003,} \mathrm{Al}$ 6061-T6, Al 7075-T6 and PA66+PA6-HI are $0,55507 \mathrm{~kg}, 0,54897 \mathrm{~kg}, 0,5693 \mathrm{~kg}$ and $0,2521 \mathrm{~kg}$ respectively. This shows that the weight of the unified component with PA66+PA6-HI is reduced by almost half of that of aluminium alloys.

- The results of finite element analyses performed for the unified part with PA66+PA6-HI material are also verified experimentally. It is shown that the experimental results confirm the results of finite element analyses.

\section{Acknowledgements}

This work is supported by TUBITAK-Turkish Scientific and Technological Research Council under the project number: 7130723.

\section{REFERENCES}

[1] X. Cui, H. Zhang, S. Wang, L. Zhang and J. Ko. Design of lightweight multi-material automotive bodies using new material performance indices of thin-walled beams for the material selection with crashworthiness consideration, Materials and Design, Vol. 32, p. 815-821, 2011.

[2] M. Merklein, and M. Geiger. New materials and production technologies for innovative lightweight constructions, Journal of Materials Processing Technology, Vol. 125-126, p. 532-536, 2002.

[3] B. E. Tonn, S. M. Schexnayder, J. H. Peretz, S. Das and G. Waidley. An assessment of waste issues associated with the production of new, lightweight, fuel-efficient vehicles, Journal of Cleaner Production, Vol. 11, p. 753-765, 2003.

[4] X. Cui, S. Wang and S. J. Hu. A method for optimal design of automotive body assembly using multi-material construction, Materials and Design, Vol. 29, p. 381-387, 2008.

[5] Y. Li, Z. Lin, A. Jiang and G. Chen. Experimental study of glass-fiber mat thermoplastic material impact properties and lightweight automobile body analysis, Materials and Design, Vol. 25, p. 579-585, 2004.

[6] S. M. Sapuan. A knowledge-based system for materials selection in mechanical engineering design, Materials and Design, Vol. 22, p. 687-695, 2001.

[7] Material Database, online available from http://www.emsgrivory.com/en/ems-material-database/emsmaterial-database-grilon/ 